\title{
Sea-ice motion in the Weddell Sea from drifting-buoy and AVHRR data
}

\author{
David Crane* \\ Global Environmental and Ocean Sciences Ltd., Swindon SN2 5AZ, England \\ Peter Wadhams \\ Scott Polar Research Institute, University of Cambridge, Cambridge CB2 IER, England
}

\begin{abstract}
A study of sea ice in the northern Weddell Sea was done, relating the ice motion, determined using an array of satellite-tracked drifters, deployed into ice floes, to parameters describing the nature of the ice cover, obtained from an analysis of Advanced Very High Resolution Radiometer (AVHRR) imagery. It was found that the ice motion was predominantly wind-driven, responding to the passage of lowpressure systems across the area. The correlation length of the strain field over the entire measurement period was around $200 \mathrm{~km}$. At high concentrations the ice responded as a rigid body with coherent motion, but below a concentration of around $93 \%$, differential motion occurred. The nature of the ice motion was found to depend upon the lead parameters, with low values of pure convergence and divergence and larger values of vorticity and deformation of the ice field. The vorticity was found to be well correlated with the atmospheric pressure, with a time lag of less than $3 \mathrm{~h}$, implying an almost instantaneous response of the ice cover to meteorological forcing.
\end{abstract}

\section{INTRODUCTION}

The Weddell Sea is an important area in the Antarctic for sea-ice formation and bottom-water generation. Parameterizing the changing nature of the ice cover in response to atmospheric and oceanographic forcing is a crucial step toward successfully modelling the atmosphere-ocean coupling and climatic effects.

There have been several studies of sea-ice motion in the Weddell Sea region (Ackley, 1981; Limbert and others, 1989; Rowe and others, 1989; Wadhams and others, 1989; Martinson and Wamser, 1990; Massom, 1992), all describing the general nature of the ice motion. Qualitative relationships with tidal and atmospheric forcing are presented and Martinson and Wamser derive figures for drag coefficients and turning angles. Ice velocity vectors from satellite imagery have been previously compared with those from drifting buoys in the Weddell Sea (Viehoff, 1991; Viehoff and $\mathrm{Li}, 1994)$, but the relationship between the ice motion and the rheology of the ice field has not been investigated.

This paper utilises two sets of data to address this problem. The first is a series of Advanced Very High Resolution Radiometer (AVHRR) images, covering parts of the Weddell Sea, collected at Palmer Station

\footnotetext{
* Formerly at Scott Polar Research Institute.
}

and made available by the Scripps Institute of Oceanography (SIO), courtesy of R. H. Whritner. The second is position and sensor data from an array of ice-mounted drifting buoys, deployed by the Alfred-Wegener-Institut für Polar-und Meerforschung (AWI) in 1989. The AVHRR data were processed to obtain floe and lead parameters which could then be compared with velocity vectors, ice-field deformation and meteorological forcing obtained from the buoy data. Figure 1 shows the area of the study, with the drifter positions and AVHRR image limits marked.

\section{AVHRR IMAGERY}

The AVHRR image data from the NOAA-10 and NOAA-11 satellites were selected to coincide with the buoy-array deployments. A series of 77 images, covering the period 19 October-5 December 1989, was examined. Of these, only nine contained cloud-free area in the vicinity of the drifter array being used. The software employed to process the images was a combination of TeraScan software (SeaSpace Corporation, San Diego, U.S.A.) and software developed in-house. The raw image was first loaded, geolocated and overlaid with a coastline and latitude-longitude grid. The desired portion of the image was selected and registered to a master file defining the area to be covered, normally $512 \times 512$ pixels (selected to be a power of 2), covering an area of $300000 \mathrm{~km}^{2}$. 


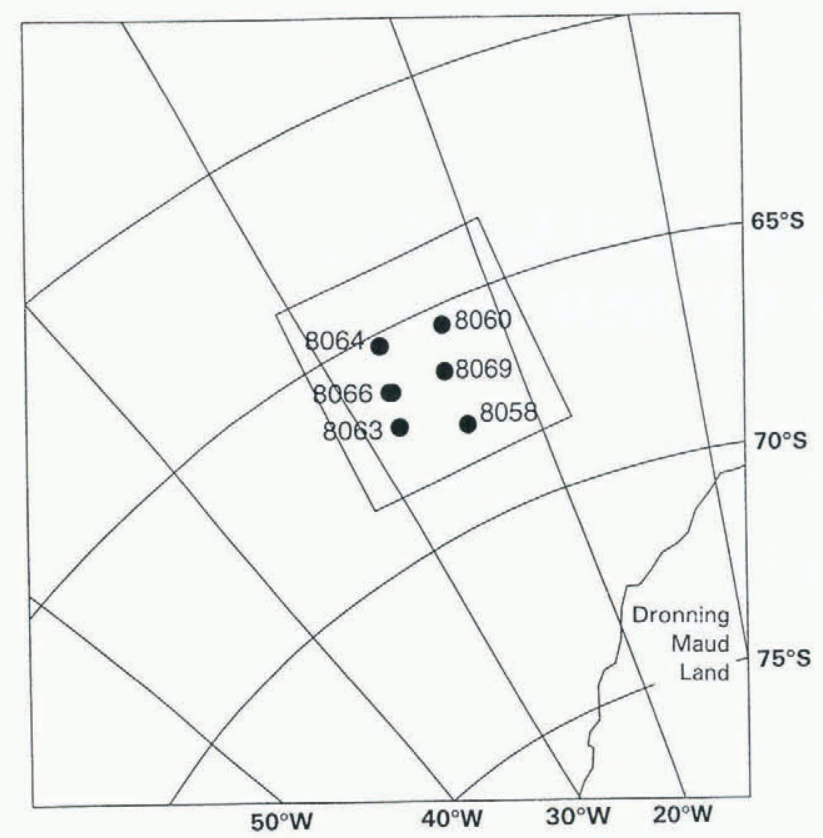

Fig. 1. Area of study in the Weddell Sea, showing the limits of the AVHRR images used and the six drifter positions.

The AVHRR imagery displayed a variation in brightness across an image, as a result of the relative angle of the sun, and it was necessary to remove this gradation before attempting to threshold the image. The brightness variation represented a wave number much lower than the variations presented by the ice-floe-water interfaces, and so the effect was removed using a high-pass three-dimensional filter. The routine to do this transformed the data into the wave-number domain, removed the power at wave numbers lower than the selected level (this was normally chosen to be three or four cycles across the whole image width) and transformed back into the space domain.

The image having been balanced, it was necessary to threshold the image to discriminate between ice and water. A problem encountered here was the presence of cloud. Previous work (e.g. Ebert, 1989; Key and Barry, 1989) has indicated that the reflective ratio between cloud and ice varies between different AVHRR channels. In this study the contrast was found to be highest on channel 4. Using this channel, the image areas which were cloud were identified by visual inspection, and rejected. The remainder of the image area was then thresholded. Figure 2 displays an image, from the area of the study shown in Figure 1, after the filtering and thresholding operation. The image was obtained on 28 October 1989, and the positions of the ice-mounted drifters are indicated.

The final step in the analysis was obtaining the floe and lead properties, in order that they could be compared with the deformation patterns. The parameters used were lead length, width, area and orientation. A recursive method was employed, whereby each feature was identified and assigned a unique code. A feature was defined as an area with continuous interconnecting pixels with the value chosen to represent water. Each feature was examined to determine its properties. The length of

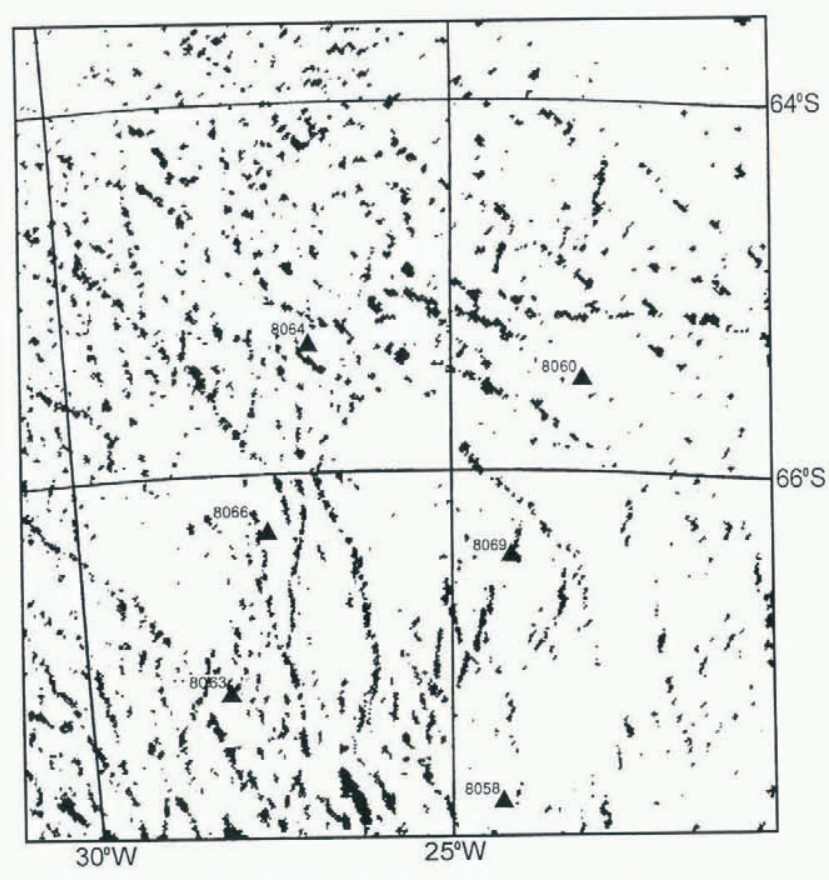

Fig. 2. Filtered, thresholded AVHRR image with the
positions of the drifters superimposed.

the feature was defined as the distance between the two farthest-spaced pixels, and the width as the mean distance between pixels at right-angles to the length. Orientation of the feature was along the long axis. Figure 3 depicts lead-orientation probability for all of the images processed. The probability is weighted by lead length to give a better indication of the area of open water in each image with a given orientation.

Errors inherent with using the automatic featureidentification algorithm stemmed from the need to set a threshold level which separated the differently orientated features in the image. To prevent a large number of interconnected leads being identified as one feature, yielding erroneous results, a relatively high threshold level was set, and fine-tuned by visual inspection. As can be seen from Figure 2, the effect of this was to create breaks in what are clearly continuous features. In many cases this was beneficial as it separated parts of a single feature with different orientations. The worry was that by breaking a long feature down into a series of shorter features, the lead-orientation probabilities might have been altered.

To investigate the effect of setting a high threshold level, the image of Figure 2 was analyzed manually, to determine the lead-orientation probability. In this analysis, breaks in obviously continuous features were identified by eye from the original unthresholded image and removed. The resulting distribution was similar to that obtained with the automatic algorithm, with around $75 \%$ of directional occurrences being in the north-south quadrant in both cases. Whereas the automatic algorithm returned a relatively even distribution of directionality around a north-south line, the results obtained with the manual analysis displayed a preference for lead orientation along a northwest-southeast axis. A comparison of ice concentration, between the two methods of analysis, indicated that the threshold level required to separate 


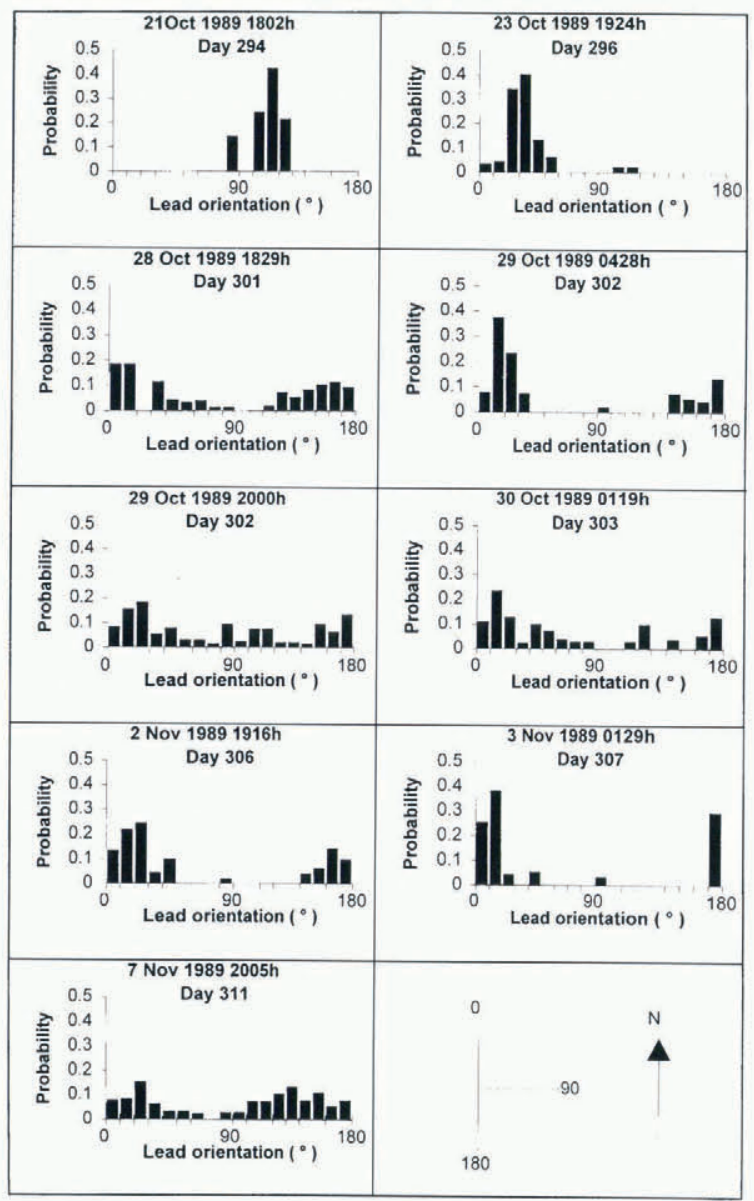

Fig. 3. Probability of lead orientation, divided into 10 bins. The orientation probability is weighted according to lead length.

individual features tended to underestimate the area of open water by about $20 \%$, giving a maximum error in the ice concentration, at the high levels measured in this study, of $2.5 \%$.

Values of sea-ice concentration, calculated as the area of ice-covered ocean as a percentage of the entire image area used for analysis, were determined for each AVHRR image processed (Fig. 4), for comparison with the ice motion. Due to the limited temporal coverage of good

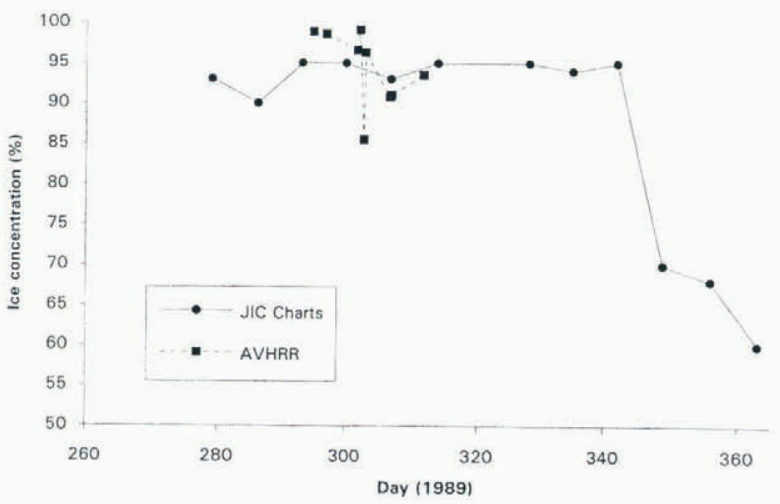

Fig. 4. Values of sea-ice concentration within the study area, determined from an analysis of AVHRR imagery and from Navy/NOAA Joint Ice Centre sea-ice charts.
AVHRR imagery, values for ice concentration were also obtained from the Navy/NOAA Joint Ice Centre (JIC) charts. Although giving a larger data set, the iceconcentration values given by these charts were very coarse, being divided into $10^{\circ}$ bins. Figures for the area studied were derived by taking the value at the centre of each concentration bin and weighting it proportionally to the fraction of area covered by that concentration. This method detects very clearly the large drop in ice concentration at the onset of spring, and shows other, smaller, variations throughout the winter. Comparison with the ice-concentration figures obtained from the AVHRR images (Fig. 4), however, shows that whilst the general trend of both methods is in agreement, the values obtained from the JIC charts underestimate the variation in sea-ice concentration.

\section{DRIFTING-BUOY DATA}

The drifter array used for this study comprised six buoys, deployed into ice floes, tracked via Service Argos. The buoy numbers and locations are shown in Figures 1 and 2 for 28 October 1989. The data were supplied by Dr C. Kottmeier (AWI), error-checked and interpolated to 3 hourly intervals. For all drifters, values for latitude, longitude, eastward and northward velocity vectors and atmospheric pressure were obtained. For drifters 8066 and 8069, in the centre of the array, air temperature, wind speed, wind direction and buoy orientation were also supplied.

A useful method of expressing the motion of the ice field, which assists in comparison with the AVHRR imagery, is in terms of the differential kinematic parameters (DKPs). The DKPs of divergence, vorticity, shearing deformation rate and normal deformation rate (or "stretch") are defined here following Molinari and Kirwan (1975) as:

$$
\begin{array}{ll}
\text { divergence }= & \left(\frac{\partial u}{\partial x}\right)+\left(\frac{\partial v}{\partial y}\right) \\
\text { vorticity }= & \left(\frac{\partial v}{\partial x}\right)-\left(\frac{\partial u}{\partial y}\right) \\
\text { shear deformation rate }= & \left(\frac{\partial v}{\partial x}\right)+\left(\frac{\partial u}{\partial y}\right) \\
\text { normal deformation rate }= & \left(\frac{\partial u}{\partial x}\right)-\left(\frac{\partial v}{\partial y}\right) .
\end{array}
$$

Physically, divergence is the rate of change of area without change of orientation or shape; vorticity is the rate of rotation without area or shape change; shearing deformation is the rate of shape change produced by differential motions of the sides of an area parallel to those sides, and stretch is the rate of shape change produced by differential motions of the sides of an area normal to those sides. The kinematic parameters were calculated for a location at the centre of the array, removing the effects of long-term drift.

At any point $(x, y)$ relative to the specified location $(0,0)$ for which the DKPs are required, the velocity may be expressed as Taylor expansions of the $x$ and $y$ comp- 
onents of the velocity:

$$
\begin{array}{r}
u=u_{0}+\left(\frac{\partial u}{\partial x}\right)_{0} x+\left(\frac{\partial u}{\partial y}\right)_{0} y+\left(\frac{\partial^{2} u}{\partial x^{2}}\right)_{0} \\
x^{2}+\left(\frac{\partial^{2} u}{\partial y^{2}}\right)_{0} y^{2}+\ldots \ldots \ldots . . . \\
v=v_{0}+\left(\frac{\partial v}{\partial x}\right)_{0} x+\left(\frac{\partial v}{\partial y}\right)_{0} y+\left(\frac{\partial^{2} v}{\partial x^{2}}\right)_{0} \\
x^{2}+\left(\frac{\partial^{2} v}{\partial y^{2}}\right)_{0} y^{2}+\ldots \ldots \ldots . . .
\end{array}
$$

(Saucier, 1955), where the subscript 0 indicates the properties at the chosen origin.

If the distances $x$ and $y$ were small, then the higherorder derivatives could be ignored and the distribution of velocity regarded as linear. However, as the values of $x$ and $y$ were large, a second-order Taylor expansion was used (the highest possible with six drifters) and the equations for all buoys solved simultaneously to obtain the values of $\partial u / \partial x, \partial u / \partial y, \partial v / \partial x$ and $\partial v / \partial y$ at the chosen point. Figure 5 shows the results of this analysis.
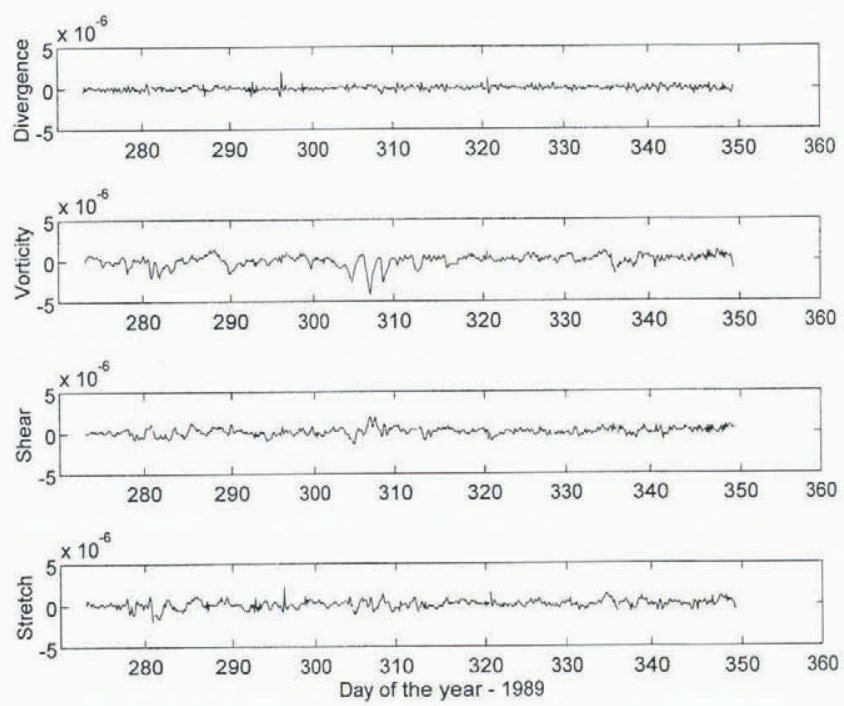

Fig. 5. Time series of divergence, vorticity, shear and stretch deformation. Vorticity events dominate, with deformation values being between two and four times smaller.

The variance of the error in estimating any of the velocity derivatives was approximately (Thorndike and Colony, 1982) $4 \sigma^{2} \Delta t^{-2} \Delta x^{-2}$, where $\sigma^{2} \approx 200 \mathrm{~m}^{2}$ was the variance in typical errors in the position measurement of the Argos-tracked drifters, $\Delta x \approx 200 \mathrm{~km}$ was the separation of the measurement points and $\Delta t$ was the time step of $3 \mathrm{~h}$. This gave a standard deviation of $2.0 \times 10^{-7} \mathrm{~s}^{-1}$. The standard deviations of the calculated deformations were $3.0 \times 10^{-7} \mathrm{~s}^{-1}$ for divergence, $6.9 \times 10$ ${ }^{7} \mathrm{~s}^{-1}$ for vorticity and $4.9 \times 10^{-7}$ and $4.5 \times 10^{-7} \mathrm{~s}^{-1}$ for shear and stretch deformation, respectively. During periods of intense deformational activity, such as days $304-310$, the standard deviation of divergence remained the same, but for vorticity, shear and stretch deformation rose to $12.2,7.8$ and $6.3 \times 10^{-7} \mathrm{~s}^{-1}$, respectively. Thus, whilst changes in the divergence were indistinguishable from the measurement error, vorticity and deformation values, especially during periods of kinematic activity, could be used with some confidence.

\section{DISCUSSION}

Figure 3 indicates that, with the exception of the first image, from 21 October, the highest probability was for a lead orientation in the north-south quadrant. This would tend to promote deformation of the ice field along the axes of the leads, giving higher values of the $\partial v / \partial x$ velocity derivative, leading to increased shear deformation and vorticity compared to pure divergence, a finding supported by the DKP values in Figure 5. This shows the magnitude of the vorticity to have been more than twice that of the divergence, with both types of deformation being about halfway in between. The rms value for vorticity was $6.9 \times 10^{-7} \mathrm{~s}^{-1}$, for divergence $3.05 \times 10^{-7} \mathrm{~s}^{-1}$ and for shear and stretch 4.5 and $4.8 \times 10^{-7} \mathrm{~s}^{-1}$, respectively.

Noticeable events of negative vorticity occurred just after day 280, at day 290, between days 304 and 310 and just before day 340 . All of these events coincided with occurrences of low atmospheric pressure near the centre of the drifter array, as well as dips in the values of ice concentration. With simple offsetting and scaling, the major features of the vorticity could be reproduced from the measurements of atmospheric pressure (Fig. 6). This indicates that the centre of the low-pressure systems must have been near the middle of the drifter array, not unexpectedly as the array is sited near the average latitude of the circumpolar trough (Deacon, 1984). At each time there occurred a positive-negative-positive shear deformation event, indicative of the differential winds of a low-pressure system passing over the region.

The largest of these events occurred between days 304 and 310 , the period covered by the AVHRR images. Figures 3 and 4 show that with the onset of this event the
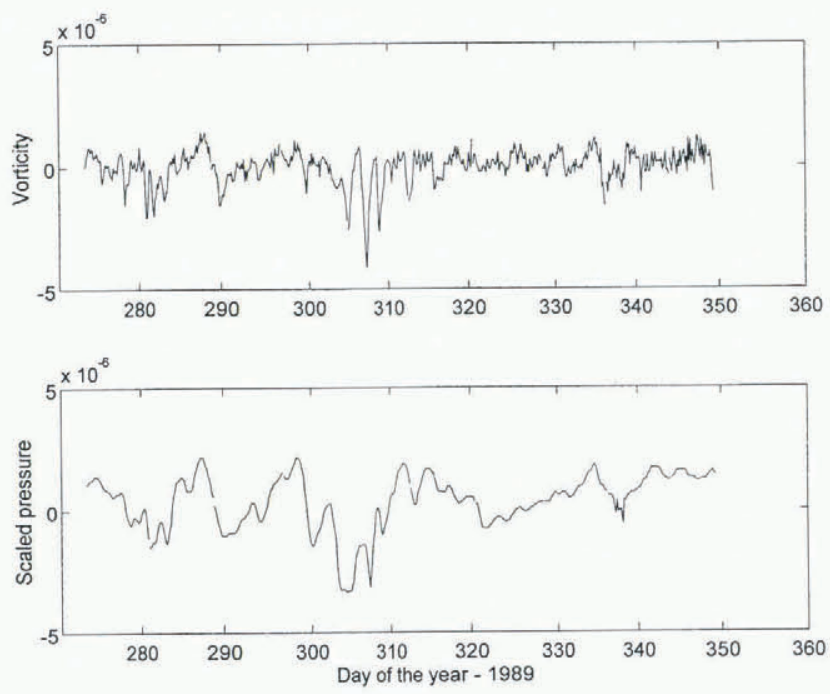

Fig. 6. Comparison of ice-field vorticity and scaled values of atmospheric pressure. Major features of negative vorticity correspond to periods of low pressure. 
ice concentration dropped, with the orientation of the developing open water being preferentially in the northsouth quadrant, peaking, in the case of both images analyzed, in a direction to the north-northeast. The lowpressure systems passing over the array at the time would have tended to induce a clockwise rotation of the ice field. The preferred lead orientation would allow motion with the wind field along a north-south axis in the western and eastern regions of the area being studied. In the north and south, however, the wind-induced motion of the ice along an east-west axis would be prevented. This is demonstrated in the significant positive shear deformation (mean of $3.3 \times 10^{7} \mathrm{~s}^{-1}$ ) over this period. Even larger values of negative vorticity (mean of $-8.2 \times 10^{-7} \mathrm{~s}^{-1}$ ) indicate a rotation of the entire ice field. These values would have induced a $10^{\circ}$ clockwise rotation in the lead orientation between days 304 and 310 . Although there is some change in the lead orientation distribution over this period (Fig. 3), it is difficult to ascertain whether there is any significant rotation of the ice field, as $10^{\circ}$ is the limit of resolution of the lead-orientation measurements. There is also the distinct possibility that, measured over the ranges of around $300 \mathrm{~km}$, as in this experiment, the vorticity is due to local shearing events, allowing the ice floes to follow the large-scale circulation of the overlying low-pressure system.

A time-lag correlation between atmospheric pressure and the array vorticity shows a peak at zero lag (Fig. 7). Each data set was smoothed with a $12 \mathrm{~h}$ running mean before analysis. Since the data were at $3 \mathrm{~h}$ intervals, this shows that the response of the sea ice to the wind was immediate (i.e. less than $3 \mathrm{~h}$ ), in contrast to delays of several hours observed in Arctic winter ice, where stress is

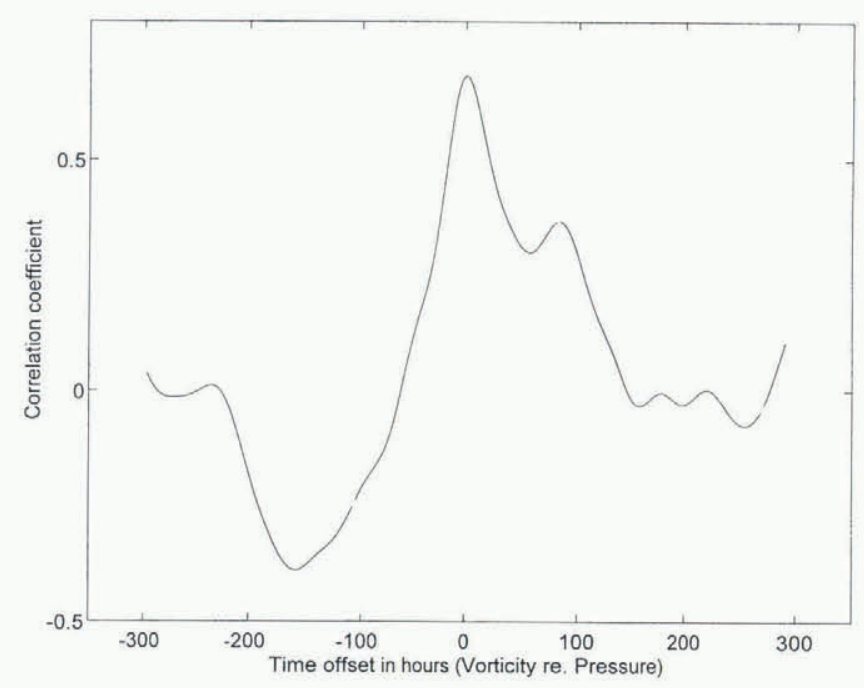

Fig. 7. Time-lagged correlation of almospheric pressure and array vorticity. The correlation peaks at a value of 0.7 at zero time lag, implying an almost instantaneous response of the ice cover to meteorological forcing.

transmitted over long distances.

Another method of quantifying the motion of the ice field is by examining the temporal and spatial correlation of the velocity components of the ice. Figure 8 shows the

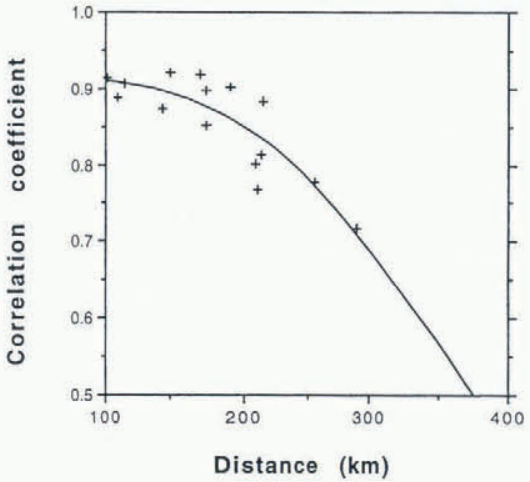

Fig. 8. Cross-correlation of the u-component velocity vectors, between pairs of drifters at different separations, showing a gradual decrease with increasing distance.

correlation of the $u$ component of the ice velocity, at different distances, for the whole period of the experiment. The ice velocity was well correlated up to distances of around $200 \mathrm{~km}$. To compare the absolute values of the velocity vectors, as well as the similarity in variance, given by the correlation coefficients, standard deviations of the differences between normalised velocity vectors were calculated. As expected, the standard deviation increased from a value of 0.3 at drifter separations of $100 \mathrm{~km}$ to 0.7 at $280 \mathrm{~km}$.

Running correlations of the $u$ velocity components of three pairs of drifters, at separations of 150, 200 and $300 \mathrm{~km}$, are shown in Figure 9. It is apparent that dips in the sea-ice concentration coincide with troughs in the velocity-component correlations for all buoy pairs. This emphasises the importance of the ice concentration to the cohesiveness of the ice field. All of these results indicate that when the ice concentration was high, above $95 \%$, the ice tended to move as a rigid body. Below concentrations of $93 \%$, differential motion became apparent, dominated by negative vorticity but with some deformation present.
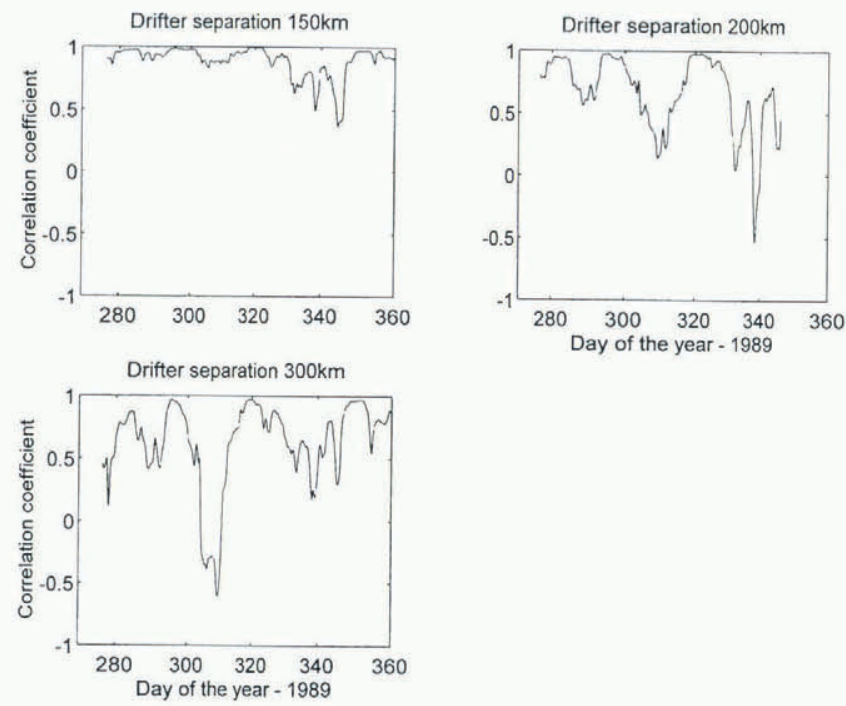

Fig. 9. Running correlations of the u-component velocity vectors, between pairs of drifters at separations of 150, 200 and $300 \mathrm{~km}$, showing lower correlation with increasing and dips in the values at times of low ice concentration. 


\section{CONCLUSIONS}

These results demonstrate the importance of both atmospheric forcing and the nature of the ice field on the kinematics of the sea-ice cover. When the sea-ice concentration was high, internal ice stress was important. The ice field acted to some extent as a rigid body, and coherent motion occurred over large distances (e.g. days 295-300; around day 320).

When the ice concentration dropped below about $93 \%$ the effect of internal stresses was reduced, the ice field stopped responding as a rigid body and differential motion occurred. The dominance of the vorticity reflected the main driving forces of the low-pressure systems passing across the study area, with the values of vorticity being correlated to those of the atmospheric pressure near the centre of the array. The lack of any obvious change in the lead orientation during vorticity events indicates that the large-scale rotation of the ice field could be the product of many local shearing events. A smaller but still significant amount of shear deformation supported this idea.

The average correlation length of the strain field was found to be around $200 \mathrm{~km}$. This is only $50 \%$ of the value found by Thorndike (1986) for Arctic sea ice. This may be due to the generally lower values of ice thickness found in the Antarctic or to the fact that, even in winter, the occurrence of leads in the Antarctic is greater than that in the Arctic.

\section{ACKNOWLEDGEMENTS}

This work was supported by funding from the U.K. Natural Environment Research Council under grant GR3/8210. The authors are indebted to Dr C. Kottmeier of the AWI for drifting-buoy data and to R. Whritner of SIO for AVHRR data. Thanks go to C. Shipman from the SPRI and S. Edwards from GEOS for providing valuable help with diagrams.

\section{REFERENCES}

Ackley, S. F. 1981. Sea-ice atmosphere interactions in the Weddell Sea using drifting buoys. International Association of Hydrological Sciences Publication 131 (Symposium at Canberra 1979-Sea Level, Ice and Climatic Change), 177-191.

Deacon, G. 1984. The Antartic circumpolar ocean. Cambridge, Cambridge University Press.

Ebert, E. E. 1989. Analysis of polar clouds from satellite imagery using pattern recognition and statistical cloud analysis scheme. J. Appl. Meteorol., 28, 382-399.

Key, J. and R.G. Barry. 1989. Cloud cover analysis with Arctic AVHRR data: 1. Cloud detection. 7. Geophys, Res., 94(D15), 18,52118,535 .

Limbert, D. W. S., S. J. Morrison, C. B. Sear, P. Wadhams and M. A. Rowe. 1989. Pack-ice motion in the Weddell Sea in relation to weather systems and determination of a Weddell Sea sea-ice budget. Ann. Glaciol., 12, 104-112.

Martinson, D. G. and C. Wamser. 1990. Ice drift and momentum exchange in winter Antarctic pack ice. 7. Geophys. Res., 95 C2), $1741-1755$.

Massom, R. A. 1992. Observing the advection of sea ice in the Weddell Sea using buoy and satellite passive microwave data. J. Geophys. Res., 97 C 10$), 15,559-15,572$.

Molinari, R. and A.D. Kirwan. 1975. Calculations of differential kinematic properties from Lagrangian observations in the western Caribbean Sea. J. Phys. Oceanogr., 5, 483-491.

Rowe, M. A., C. B. Sear, S.J. Morrison, P. Wadhams, D. W. S. Limbert and D. R. Crane. 1989. Periodic motions in Weddell Sea pack ice. Ann. Glaciol., 12, 145-151.

Saucier, W.J. 1955. Principles of meteorological analysis. Chicago, IL, University of Chicago Press.

Thorndike, A.S. 1986. Kinematics of sea ice. In Untersteiner, N., ed. Geophysics of sea ice. London, etc., Plenum Press, 489-549. (NATO ASI Series B: Physics 146.

Thorndike, A.S. and R. Colony, 1982. Sea ice motion in response to geostrophic winds. 7. Geophys. Res., 87 C8), 5845-5852.

Viehoff, T. 1991. Sea ice observations in the Weddell Sea. In Proceedings of the Fifth AVHRR Data Users Meeting, Tromso, Norway, 2528 June 1991. EUM PO9, 483-489.

Viehoff, T. and A. Li. 1994. Multi-sensor and ground-truth investigation of Weddell Sea ice conditions. In Space at the Service of our Environment. Proceedings of the Second ERS-1 Symposium, 11-14 October 1993, Hamburg, Germany. Vol. 1. Paris, European Space Agency, 287-290. (ESA SP-361.)

Wadhams, P., C. B. Sear, D. R. Crane, M. A. Rowe, S.J. Morrison and D. W.S. Limbert. 1989. Basin-scale ice motion and deformation in the Weddell Sea during winter. Ann. Glaciol., 12, 178-186. 